\title{
Genotypic differences for temperature response of leaf appearance rate and leaf elongation rate in field-grown maize
}

\author{
C Giauffret ${ }^{1 *}, \mathrm{R}$ Bonhomme ${ }^{2}, \mathrm{M}$ Derieux ${ }^{1}$ \\ 1 INRA, laboratoire de génétique et d'amélioration des plantes, F80200 Estrées-Mons; \\ 2 INRA, unité de recherche en bioclimatologie, F78850 Thiverval-Grignon, France
}

(Received 12 April 1994; accepted 24 March 1995)

\begin{abstract}
Summary - Leaf area establishment is the main factor limiting the yield of maize (Zea mays $\mathrm{L}$ ) in areas characterized by long cool springs such as in northern Europe. The objective of this research was therefore to study the influence of temperature on leaf area growth and development processes. Unlike most of the previous studies, it was conducted under field conditions and emphasized genetic variability for traits related to cold tolerance. Twelve genotypes of maize were planted in northern France on 4 April 1991 (early planting date) and 10 May 1991 (normal-to-late planting date). Leaf tip appearance rate and leaf elongation rate (for leaves 6, 9 and 12) were evaluated over successive periods of 3-4 $\mathrm{d}$ and related to environmental data. Among the genotypes studied, the mean leaf tip appearance rate varied from 0.17 to 0.22 leaf tip $\mathrm{d}^{-1}$. The mean leaf elongation rate varied from 10 to $21 \mathrm{~mm} \bullet \mathrm{d}^{-1}$ for leaf 6 , and from 29 to $58 \mathrm{~mm} \cdot \mathrm{d}^{-1}$ for leaf 9 . Leaf tip appearance rate was linearly related to mean soil temperature $\left(R^{2}=0.47\right)$. Leaf elongation rates were almost exclusively determined by mean soil temperature $\left(R^{2}>0.85\right)$. Among the genotypes evaluated, the apparent temperature threshold varied from 7.1 to $12.6^{\circ} \mathrm{C}$ for leaf tip appearance rate, from 8.3 to $12.8^{\circ} \mathrm{C}$ for elongation rate of leaf 6 , and from 7.1 to $13.5^{\circ} \mathrm{C}$ for elongation rate of leaf 9 . It was possible to define a degree of tolerance to temperature variation for each genotype. Such results could help the breeder to select genotypes able to withstand cool spring conditions, and should be included in genotype-specific crop growth simulation models.
\end{abstract}

maize / leaf growth / development / temperature

Résumé - Différences génotypiques dans la réponse à la température du rythme d'apparition des feuilles et de la vitesse d'allongement foliaire pour du maïs cultivé en conditions de plein-champ. La mise en place du système foliaire est le principal facteur limitant le rendement dans les régions caractérisées par un printemps long et frais telles que l'Europe du Nord. L'objectif de ce travail était d'étudier l'influence de la température sur le développement et la croissance foliaires. À la différence de la plupart des études antérieures, il a été conduit en conditions de plein champ et l'accent a été mis sur la variabilité génétique pour différents caractères de tolérance au froid. Douze génotypes de maïs ont été semés dans le nord de la France le 4 avril 1991 (semis précoce) et le 10 mai 1991 (semis normal à tardif). Le rythme d'apparition des jeunes feuilles et la vitesse d'allongement foliaire (feuilles de rang 6, 9 et 12) ont été estimés sur des périodes successives de 3 ou $4 \mathrm{j}$. Pour les génotypes étudiés, le rythme moyen d'apparition des feuilles variait de 0,17 à 0,22 feuille par jour. La vitesse moyenne d'allongement foliaire variait de 10 à $21 \mathrm{~mm}$ par jour pour la feuille 6 et de 29 à $58 \mathrm{~mm}$ par jour pour la feuille 9. Le rythme d'apparition des feuilles était lié de façon

\footnotetext{
* Correspondence and reprints
} 
linéaire à la température moyenne du sol $\left(\mathrm{R}^{2}=0,47\right)$. Les vitesses moyennes d'allongement étaient presque exclusivement déterminées par la température moyenne du sol $\left(\mathrm{R}^{2}>0,85\right)$. Parmi les génotypes étudiés, la température seuil variait de 7,1 à $12,6^{\circ} \mathrm{C}$ pour le rythme d'apparition des feuilles; de 8,3 à $12,8^{\circ} \mathrm{C}$ pour la vitesse d'allongement de la $6^{e}$ feuille ; de 7,1 à $13,5^{\circ} \mathrm{C}$ pour la vitesse d'allongement de la $9 e$ feuille. Il a été possible de définir pour chaque génotype un indice de tolérance aux variations de température. De tels résultats devraient permettre au sélectionneur d'obtenir des génotypes adaptés aux conditions de printemps frais et pourraient être intégrés dans des modèles de simulation spécifiques du génotype.

maïs / développement / croissance foliaire / température

\section{INTRODUCTION}

Only early maize cultivars can be grown in northern Europe, because of the limited amount of thermal time available during the growing season. Yields are low because these cultivars have a reduced capacity to intercept solar radiation. There are 2 reasons: (i) their maximum leaf area index (LAI) is lower than 4 , whereas maximum light interception requires a larger LAI (VarletGrancher et al, 1982); and (ii) the maximum LAl is reached at flowering time (end of July) when the available solar radiation is already decreasing. One solution for the farmer could be to sow at earlier dates but using hybrids with higher cold tolerance.

Leaf area establishment is characterized by (i) the rate of emergence of new leaves and the duration of the vegetative phase, which together determine the total number of leaves; and (ii) the rate and duration of growth in area for each leaf. Temperature effects on these characters have been studied by many authors, mainly in controlled environments, but with little emphasis on genetic variability. Temperature is the main environmental factor affecting leaf tip appearance rate. This rate is determined by the apex temperature, ie the soil temperature prior to stem elongation, and the air temperature thereafter (Brouwer et al, 1973). Tollenaar et al (1979) reported that the response of leaf tip appearance rate to temperature is linear between 12 and $26^{\circ} \mathrm{C}$, with an optimum around $31^{\circ} \mathrm{C}$. The duration of the leaf emergence phase (time elapsed between the emergence of the coleoptile and the emergence of the last leaf from the whorl) has been studied much less frequently than the duration between sowing and silking or anthesis. Nevertheless the lengths of these intervals are closely related to temperature, allowing thermal time to be used for predicting flowering dates over a wide range of environments (Gilmore and Rogers, 1958; Cross and Zuber, 1972; Derieux and Bonhomme, 1982).

The leaf elongation rate is also strongly influenced by both soil and air temperatures. Watts
(1972) described a response curve which was essentially linear between 5 and $30^{\circ} \mathrm{C}$. The duration of leaf expansion decreases at higher temperatures; Hesketh and Warrington (1989) found that the reciprocal of the duration of extension has a linear relationship with temperature between 12 and $30^{\circ} \mathrm{C}$.

The objective of our study was to investigate the relationships between leaf development and growth processes and temperature. We were especially interested in the range $12-25^{\circ} \mathrm{C}$, which is usually encountered during autotrophic growth of maize in northern Europe. We tried to determine the effect of cool temperature $\left(12-15^{\circ} \mathrm{C}\right)$ on leaf area establishment. The study was conducted under field conditions in order to test a large number of genotypes and plants per genotype, but also to determine whether or not it was possible to define the influence of temperature independently from the variation due to the other environmental factors. Different genotypes were used for quantifying genetic variation. We did not use the simulation models based on thermal time calculations and unique temperature threshold (Hodges and Evans, 1992; Stewart and Dwyer, 1994), but we tried to evaluate genotypic differences for temperature thresholds.

\section{MATERIALS AND METHODS}

\section{Plant material}

The experiment involved 12 genotypes of maize (table I). The F257, F2 and F244 lines are early inbreds that are commercially available in Europe; they were selected in cold environments, and F244 is known to show early vigor. W64A and B73 are later-maturing commercial inbreds from the United States. LP and LT are experimental inbreds, one early and one late. These 7 inbreds were as genetically diverse as possible. Four dent $x$ flint hybrids, resulting from the cross between the previous earliest-maturing inbreds, were included: F257 x F244, F244 x F2, LP x F257, and LP $x F 2$. POOL 4, a random mating population developed by CIMMYT was also studied. It is derived from high- 
Table I. Description of the 12 maize genotypes grown in the north of France in 1991.

\begin{tabular}{|c|c|c|c|c|}
\hline Genotype & Description & Origin & $\begin{array}{c}\text { Thermal time } \\
\text { between emergence } \\
\text { and silking a }\left({ }^{\circ} \mathrm{C} \cdot d\right)\end{array}$ & $L A I^{\mathrm{b}}$ \\
\hline F257 & Early flint inbred line & INRA ${ }^{c}$, France & 746 & 1.37 \\
\hline $\mathrm{F} 2$ & Early flint inbred line & INRA, France & 808 & 1.89 \\
\hline F244 & Early dent inbred line & INRA, France & 822 & 2.37 \\
\hline LP & Early dent inbred line & Experimental & 855 & 2.84 \\
\hline W64A & Mid-late dent inbred line & Wisconsin University, USA & 966 & 2.38 \\
\hline LT & Late dent inbred line & Experimental & 1025 & 3.07 \\
\hline B73 & Late dent inbred line & lowa State University, USA & 1087 & 3.19 \\
\hline $\mathrm{F} 257 \times \mathrm{F} 244$ & Early single-cross hybrid & & 719 & 3.39 \\
\hline $\mathrm{F} 244 \times \mathrm{F} 2$ & Early single-cross hybrid & & 695 & 3.61 \\
\hline LP $\times$ F257 & Early single-cross hybrid & & 686 & 3.38 \\
\hline $\mathrm{LP} \times \mathrm{F} 2$ & Early single-cross hybrid & & 698 & 3.87 \\
\hline POOL4 & Highland semi-flint population & CIMMYT d, Mexico & 916 & 5.25 \\
\hline
\end{tabular}

a Mean for the 2 planting dates (4 April 1991 and 10 May 1991) in the north of France. Daily thermal time was estimated by the formula $D T T=T M-T T$, where TM is the mean daily temperature and TT is the temperature threshold $\left(6^{\circ} \mathrm{C}\right) .{ }^{b}$ Leaf area index at silking, evaluated at a theoretical density of 100000 ha $^{-1}$ for the 2 planting dates. ${ }^{c}$ Institut National de la Recherche Agronomique. d Centro Internacional de Mejoramiento de Maíz y Trigo.

land germplasm and was thought to be a good source of cold tolerance.

\section{Experimental design}

The studies were conducted in 1991 at the experiment station of the Institut National de la Recherche Agronomique (INRA), near Péronne in the north of France $\left(49.8^{\circ} \mathrm{N}\right)$. The 12 genotypes were evaluated in a randomized complete block design with 3 replications. The experimental unit was a 12-row plot, $4.2 \mathrm{~m}$ long with $0.8 \mathrm{~m}$ between rows. The observations detailed below were taken in 1 of the central rows, for which border rows were left on each side. The maize was planted at a density of 100000 plants ${ }^{-1} a^{-1}$, on a clay-loam soil fertilized with $195 \mathrm{~kg}^{\circ} \mathrm{ha}^{-1}$ of $\mathrm{N}, 100 \mathrm{~kg}^{\circ} \mathrm{ha}^{-1}$ of $\mathrm{P}_{2} \mathrm{O}_{5}$, and $300 \mathrm{~kg}^{\circ} \mathrm{a}^{-1}$ of $\mathrm{K}_{2} \mathrm{O}$. Weeds were completely controlled and no disease was observed prior to flowering. The volume of crop-available water was evaluted for the upper $60 \mathrm{~cm}$ of soil at $110 \mathrm{~mm}$, and irrigation was applied to ensure that at least half this amount was present for the duration of the experiment. The planting dates were 4 April 1991 and 10 May 1991; the first one, which is early for this area, was chosen to study the behavior of the genotypes at low temperature.

\section{Data collection}

The date of emergence of the coleoptile was recorded for each plant. For each row, the day on which the greatest number of plants emerged was identified, and 10 of the plants that emerged on this day were tagged for subsequent observations.

The number of visible leaves and the number of fully expanded leaves were recorded twice weekly for each tagged plant from emergence to tassel appearance. The coleoptile itself was not included in the count. A leaf was accepted as visible if its tip appeared out of the whorl when observed from the side of the plant. Wires placed above leaf 5 and leaf 10 as soon as their ligule emerged ensured that the count continued to include the leaves that were shed from the lower nodes. From one observation to the next, the increase in the number of visible leaves was noted for each plant. The mean increase within a replication was related to the time interval between the observations $(3-4 \mathrm{~d})$ and this rate was used as an estimation of the leaf tip appearance rate (leaf tip ${ }^{-1}{ }^{-1}$ ). Leaf tip appearance rate was considered to be unaffected by the stage of development, in agreement with the observations of Brouwer et al (1973) and Thiagarajah and Hunt (1982). This was verified in our case; during the whole vegetative period, the number of leaf tips was linearly related to cumulated degree-days. The total number of leaves was recorded at flowering.

Leaf length was measured twice weekly for 3 leaves on each of the tagged plants. These distances recorded were from the tip of the growing leaf to the ligule of a lower, fully expanded leaf, which was considered to be a fixed reference point: ligule 2 for leaf 6 , ligule 5 for leaf 9 , and ligule 6 for leaf 12. In fact, for leaves 9 and 12, the measurements included a component of stem elongation. For each individual leaf, the data were plotted 
against thermal time. Only those points graphically falling in the linear portion of this relationship with thermal-time were accepted for the calculation of the elongation rate. The elongation rate was then determined for each time interval between 2 observations, as the mean increase of leaf length related to the time elapsed. The final leaf area for each of the studied leaves was estimated by the product: length $x$ maximum width $\times 0.75$.

Soil temperature was recorded hourly, for each of the 2 planting dates, by 4 thermistors placed at a depth of $3 \mathrm{~cm}$. The meteorological station was about $500 \mathrm{~m}$ from the experiment but in the same open flat area; it provided relatively reliable values for air temperature ( $2 \mathrm{~m}$ above the soil) and solar irradiance on a $3 \mathrm{~h}$ basis. For each interval between observations, the following environmental data were determined: mean, maximum and minimum soil temperature $\left({ }^{\circ} \mathrm{C}\right)$; mean soil temperature during the 10 previous days $\left({ }^{\circ} \mathrm{C}\right)$; mean, maximum and minimum air temperature $\left({ }^{\circ} \mathrm{C}\right)$; daily solar radiation (MJ.m- $\mathrm{m}^{-2}$; and daylength (h).

\section{Statistical analysis}

A general linear model analysis was performed, with genotypes, sowing dates, and replications as class variables (factors), and environmental data as continuous variables (covariates). For example, with 1 covariate, the model was written:

$$
\begin{aligned}
V_{i j k}= & \mu+G_{i}+D_{j}+B_{j k}+(G D)_{i j} \\
& +\beta t_{i j}+\beta_{i} t_{i j}+\beta_{j} t_{i j}+\beta_{i j} t_{i j}+E_{i j k}
\end{aligned}
$$

where $\mu$ is the average intercept, $G_{i}$ is the effect on the intercept for the $i$ th genotype, $D_{i}$ is the effect on the intercept for the $j$ th planting date, $B_{j k}$ is the effect on the intercept for the $k$ th block within the $j$ th planting date, $(G D)_{i j}$ is the interaction between the $i$ th genotype and the $j$ th planting date, $t_{i j}$ is the value of the covariate for the th genotype and the $j$ th planting date, $\beta$ is the average slope, $\beta_{i}$ is the effect on the slope for the $i$ th genotype, $\beta_{j}$ is the effect on the slope for the $j$ th planting date, $\beta_{i j}$ is the interaction effect on the slope, and $E_{i j k}$ is the residual error. Because regression relationships that differ among the levels of a factor reflect an interaction between that factor and the covariate, such interaction terms were introduced to test the homogeneity of slopes between the different levels of each factor (Freund et al, 1986). The average intercept $\left(\mu+G_{i}\right)$ and slope $\left(\beta+\beta_{i}\right)$ of the linear relationship were estimated for each genotype. For these 2 parameters, all the contrasts relative to the difference between the estimates for 2 genotypes were calculated and tested ( $t$-test). When the difference was not significant according to this test, the genotypes were grouped together.

\section{Measure of temperature tolerance}

The statistical parameters mentioned above have no obvious biological meaning. A parameter derived from these parameters is often quoted: the apparent temperature threshold (ATT). The ATT is defined as the $x$ axis intercept of the regression line for leaf tip appearance rate of leaf elongation rate on temperature. It has no meaning as far as biological temperature threshold is concerned, because the relationship with temperature is not linear below $12^{\circ} \mathrm{C}$. However the ATT can be used with the slope to characterize regression lines derived for the range $12-25^{\circ} \mathrm{C}$.

We wanted to compare the stability of the different genotypes to temperature, and we were particularly interested in their tolerance to cool temperatures. We therefore introduced a measure of tolerance, derived from the response parameters estimated by the statistical model. This was defined as the ratio between the mean expression of the temperature-dependent character at $15^{\circ} \mathrm{C} v s$ the mean expression of the same character at $20^{\circ} \mathrm{C}$. The value of $15^{\circ} \mathrm{C}$ was chosen to represent a cool temperature, and was thought to be close to the minimum temperature for autotrophic growth in maize (Hardacre and Eagles, 1980). The value of $20^{\circ} \mathrm{C}$ was reasonably close to the favorable temperature range while still being in the range for which experimental points were observed and for which the statistical model was valid. No statistical test was possible for this new parameter, whose distribution of probability is unknown. This ratio gave an estimation of the degree of tolerance of the genotype to temperature variations. It is obvious (fig 1) that genotypes with the same degree of tolerance show the same ATT.

\section{RESULTS AND DISCUSSION}

\section{Leaf tip appearance rate}

All the environmental variables were tested to explain the variation in leaf tip appearance rate. The maximum coefficient of determination was obtained with mean soil temperature, followed in descending order of importance by maximum soil temperature, mean air temperature, maximum air temperature, minimum soil temperature, minimum air temperature, daily solar radiation, air temperature range, mean soil temperature during the previous $10 \mathrm{~d}$, photoperiod and soil temperature range. However, the part of the variation in leaf tip appearance rate unexplained by soil temperature remained large $(52.7 \%)$; figure 2 gives an example of the relationship for the hybrid LP $x$ F257. Mean soil temperature during the previous $10 \mathrm{~d}$, photoperiod, solar radiation, and soil temperature range all had a significant influence on leaf appearance rate and explained an additional $6 \%$ of the total variation. The apex temperature, had it been measured, could have provided a more accurate way of predicting the leaf tip appearance rate (Cellier et al, 1993). 


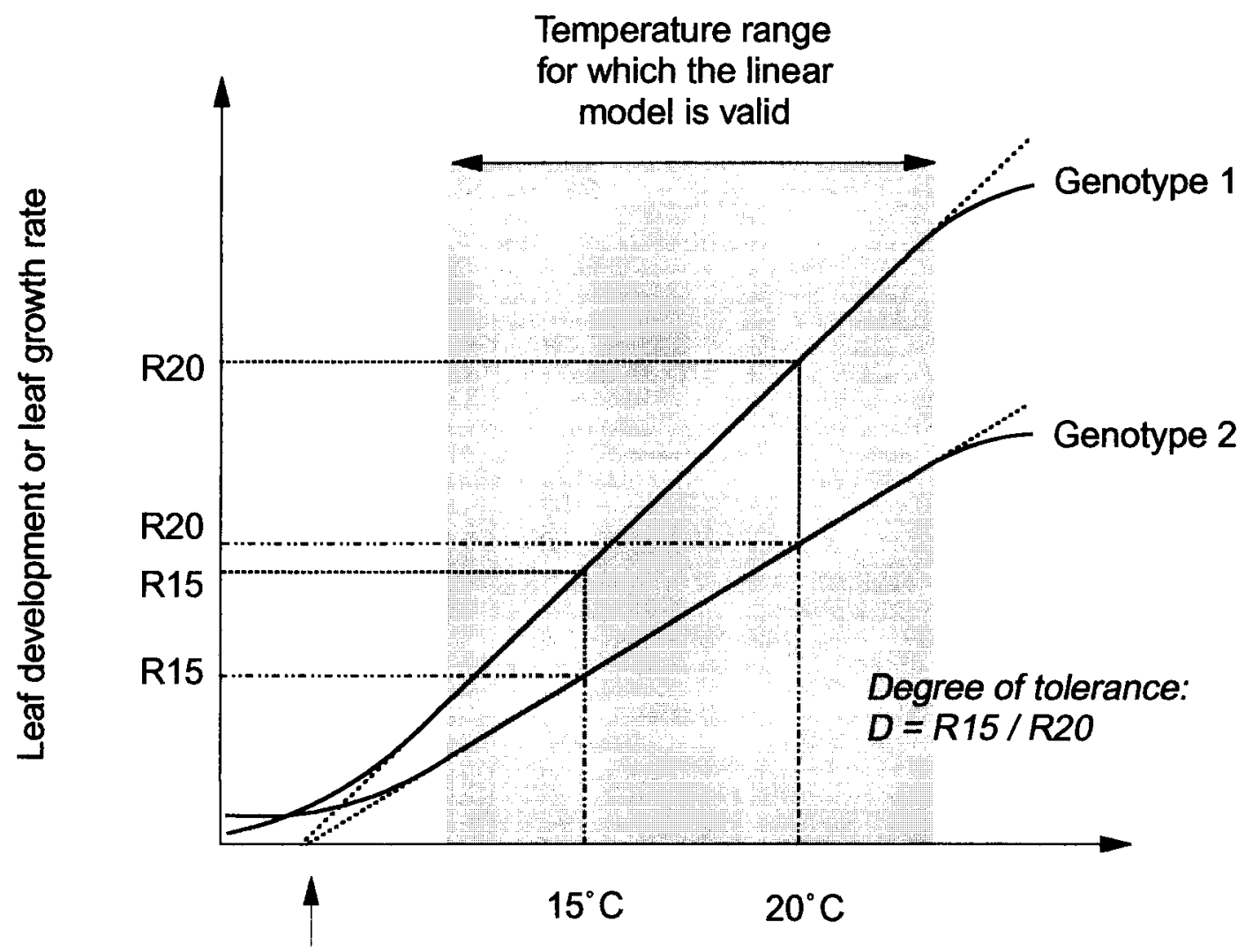

\section{Apparent temperature} threshold

Fig 1. Theoretical responses to temperature for 2 genotypes with identical degrees of tolerance to temperature variation. The degree of tolerance for a temperature-dependent character was defined as the ratio between the mean expression of the character at $15^{\circ} \mathrm{C} v \mathrm{~s}$ the mean expression of the character at $20^{\circ} \mathrm{C}$

Our values for leaf appearance rate under field conditions were lower than those obtained by Tollenaar et al (1979), Thiagarajah and Hunt (1982), and Hesketh and Warrington (1989) under controlled conditions or by Tollenaar et al (1984) under field conditions (fig 3). This could be due to the temperature measured in the various works (soil, air or apex).

In the following results, mean soil temperature was used as the only covariate (table II). General linear model analysis revealed that genotypes had significantly different reactions to temperature variation. They were classified in 2 distinct groups (table III). One group (F244, POOL4, LP x F257, and F244 x F2) showed low slopes and slightly negative intercepts; these genotypes reacted only slightly to temperature variation. The other group (F257 x F244, and all the inbreds except F244) showed high slopes and highly negative intercepts; these genotypes were susceptible to temperature variation.

According to Levitt's terminology (1980) based on analogies between physical and biological systems, the temperature response could be interpreted in terms of elastic strain. An elastic strain is reversible as soon as the stress is removed. In our case, cool periods alternated with warm periods. Leaf tip appearance rate was then reduced by decreasing temperature, but returned to higher levels when the temperature rose again as if there had been no variation. The measure of tolerance we described above is therefore a measure of the elastic tolerance of the genotype. The values are reported in table IV and, once again, the genotypes separated into the same 2 groups; the measure of tolerance was higher than $50 \%$ for the 'tolerant' group and lower than $50 \%$ for the 'susceptible' group. To some extent, the ATT defined above as a purely statistical parameter of the regression lines and reported in table IV, also indicated the degree of tolerance of the different genotypes: F244, POOL4, LP $\times$ F257, and F244 x F2, described as 'tolerant' genotypes, also showed an ATT below $10^{\circ} \mathrm{C}$. The ATTs for the tolerant hybrids were close to the $8.6^{\circ} \mathrm{C}$ proposed by Hesketh and 


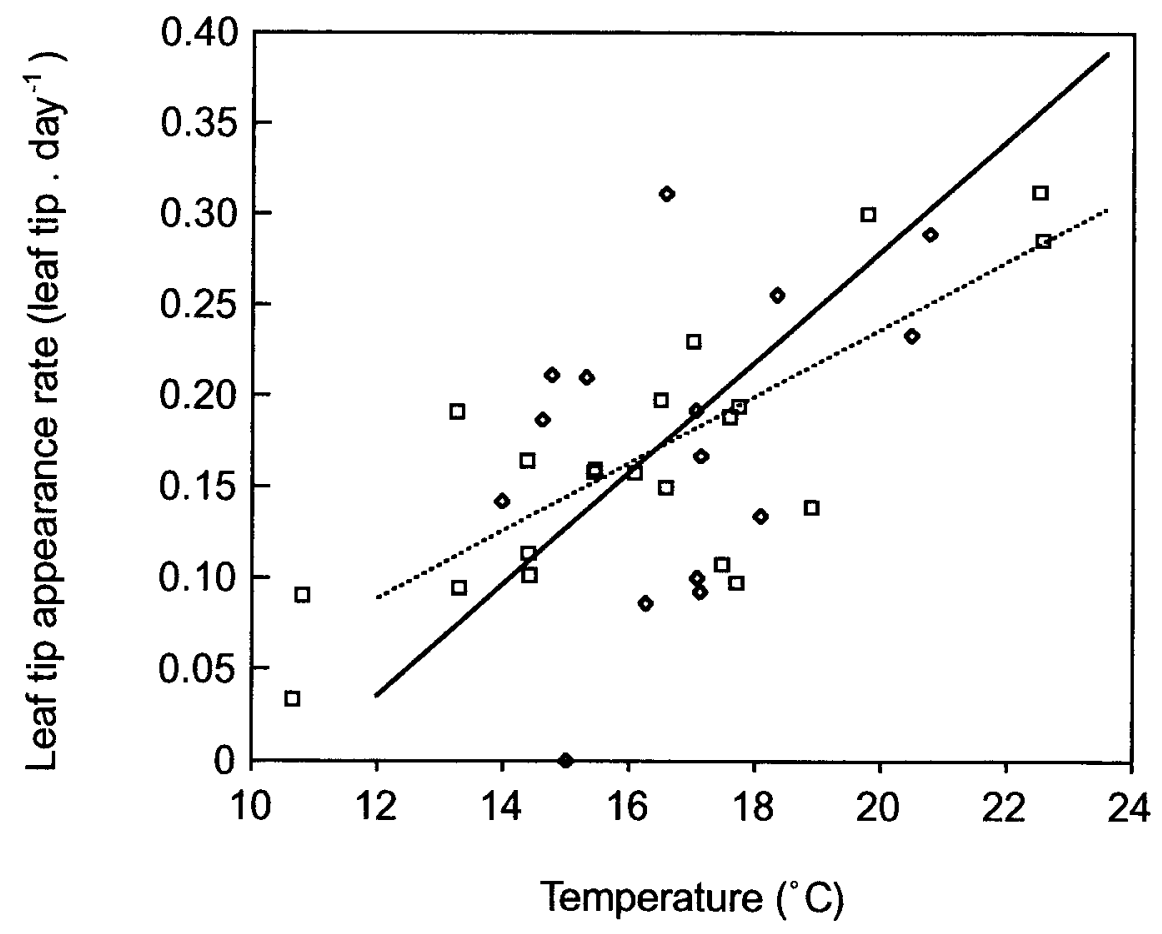

Fig 2. Leaf tip appearance rate of the maize hybrid LP x F257 in relation to mean soil temperature after early planting (4 April 1991) and late planting (10 May 1991) in the north of France. The means plotted were calculated from different numbers of observations depending on the temperature, while the regression lines were estimated from individual values; ---- $\square---$ early planting date, $Y=$ $-0.134+0.0186 X ;-$ late planting date, $Y=-0.328+0.0304 X$

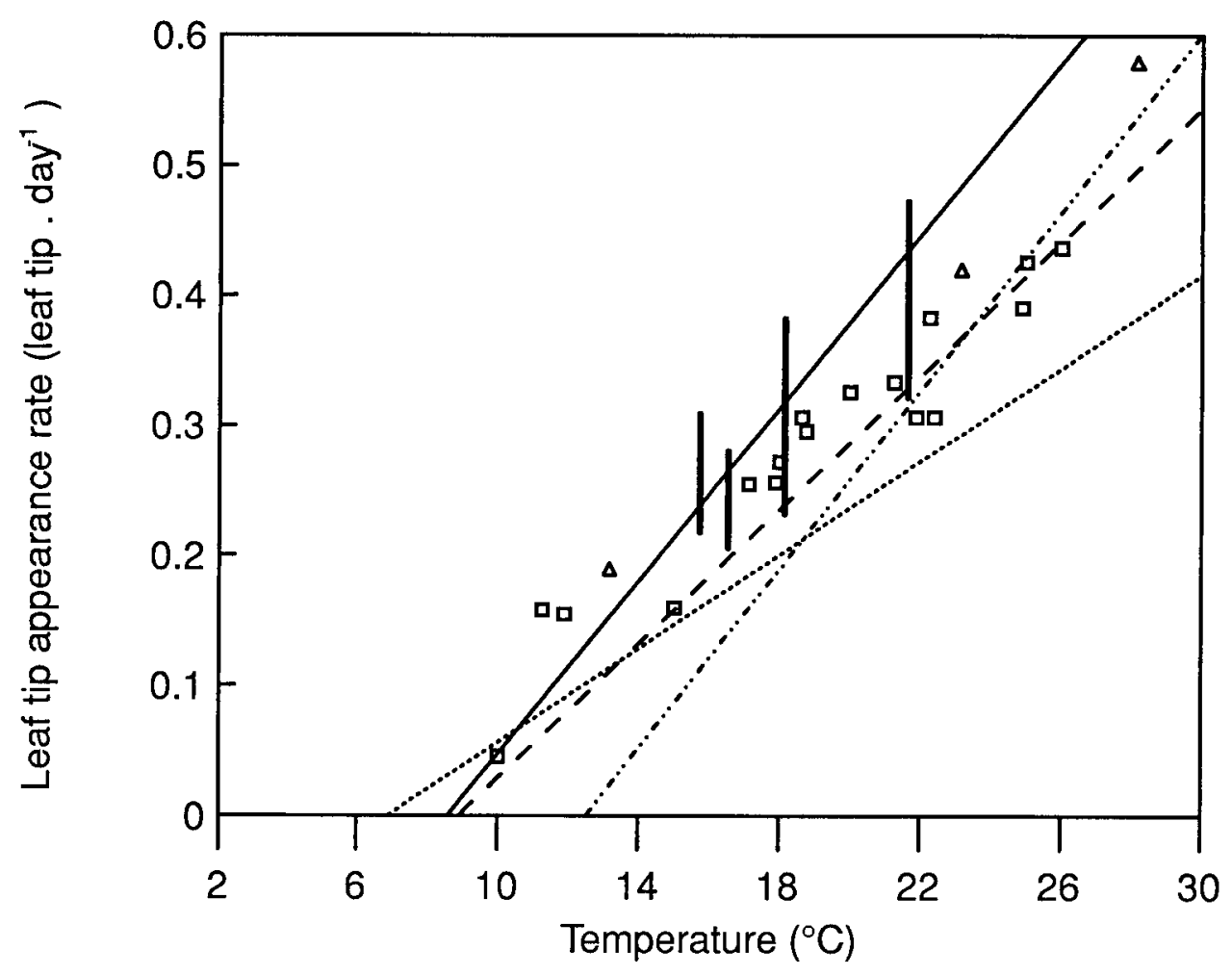

Fig 3. Relationships between maize leaf tip appearance rate and temperature derived from field or controlled-environment studies. $\square$ : Tollenaar et al (1979); controlled conditions. $\Delta$ : Thiagarajah and Hunt (1982); controlled conditions. - - Hesketh and Warrington (1989); controlled conditions. I: Tollenaar et al (1984); field conditions; range for 10 hybrids. --- POOL4, ----. F244, -........- F2: mean regression line for 2 planting dates in the north of France in 1991. 
Table II. General linear model analysis on leaf tip appearance rate using mean soil temperature as a covariate, for 12 maize genotypes grown at 2 planting dates in the north of France in 1991.

Source of variation $\quad$ Df $\quad$ Mean square F value

Temperature
Genotype
Planting date
Temperature x genotype
Temperature x planting date
Genotype x planting date
Temperature x genotype x planting
Error
Mean
CV
$R^{2}$

${ }^{*},{ }^{* *},{ }^{* * *}$ significant at the $0.05,0.01$ and 0.001 probability levels, respectively.

Table III. Estimate, standard error (SE), and grouping for the parameters of the general linear model analysis performed on leaf tip appearance rate using mean soil temperature as covariate, for 12 maize genotypes grown at 2 planting dates in the north of France in 1991.

\begin{tabular}{|c|c|c|c|c|c|c|}
\hline \multirow[t]{2}{*}{ Genotype } & \multicolumn{3}{|c|}{ Intercept (leaf tip. $\left.\alpha^{-1}\right)$} & \multicolumn{3}{|c|}{ Slope (leaf tip. $d^{-1} \cdot{ }^{\circ} \mathrm{C}^{-1}$ ) } \\
\hline & Estimate & $S E$ & Grouping a & Estimate & $S E$ & Grouping a \\
\hline $\mathrm{F} 257 \times \mathrm{F} 244$ & -0.29 & \pm 0.048 & abc & 0.0284 & \pm 0.0028 & $a b$ \\
\hline F244 x F2 & -0.25 & \pm 0.048 & bcd & 0.0259 & \pm 0.0028 & bc \\
\hline $\mathrm{LP} \times \mathrm{F} 257$ & -0.23 & \pm 0.048 & $\mathrm{~cd}$ & 0.0245 & \pm 0.0028 & bc \\
\hline $\mathrm{LP} \times \mathrm{F} 2$ & -0.27 & \pm 0.049 & $\mathrm{bc}$ & 0.0263 & \pm 0.0028 & $a b$ \\
\hline POOL4 & -0.23 & \pm 0.050 & $c d$ & 0.0258 & \pm 0.0029 & $a b c$ \\
\hline F257 & -0.38 & \pm 0.057 & $a b$ & 0.0324 & \pm 0.0032 & $a b$ \\
\hline $\mathrm{F} 2$ & -0.43 & \pm 0.057 & a & 0.0344 & \pm 0.0032 & a \\
\hline F244 & -0.12 & \pm 0.050 & d & 0.0180 & \pm 0.0029 & $\mathrm{c}$ \\
\hline LP & -0.32 & \pm 0.053 & $a b c$ & 0.0290 & \pm 0.0030 & $a b$ \\
\hline W64A & -0.29 & \pm 0.055 & $a b c$ & 0.0279 & \pm 0.0031 & $a b$ \\
\hline LT & -0.27 & \pm 0.052 & $\mathrm{bc}$ & 0.0261 & \pm 0.0029 & $a b$ \\
\hline B73 & -0.33 & \pm 0.053 & $a b c$ & 0.0300 & \pm 0.0029 & $a b$ \\
\hline Average & -0.28 & \pm 0.015 & & 0.0274 & \pm 0.0008 & \\
\hline
\end{tabular}

a For 2 estimates followed by the same letter, the contrast relative to their difference is not significantly different from zero at the 0.05 probability level.

Warrington (1989), but higher than the $5-6^{\circ} \mathrm{C}$ derived from Tollenaar et al (1979) or Thiagarajah and Hunt (1982). The range among genotypes for leaf tip appearance rate was also narrower than the range found by Tollenaar et al (1984) for 10 hybrids over 4 different periods characterized by different mean temperatures (fig 3).

The effect of planting date on leaf tip appearance rate was highly significant for both intercept and slope (table II). The early planting date showed a higher intercept $(-0.236$ vs -0.331$)$ and 
Table IV. Degree of tolerance to temperature variation, apparent threshold temperature (ATT), and mean leaf tip appearance rate for genotypes grown in the north of France in 1991.

\begin{tabular}{|c|c|c|c|c|}
\hline Genotype & $\begin{array}{c}\text { Tolerance degree a } \\
(\%)\end{array}$ & $\begin{array}{l}A T T^{\mathrm{b}} \\
\left({ }^{\circ} \mathrm{C}\right)\end{array}$ & Mean leaf & ce rate \\
\hline$\cdots$ & $\cdots$ & - & - & \\
\hline$F 257 \times F 244$ & 49.6 & 10.1 & 0.21 & 0.01 \\
\hline $\mathrm{F} 244 \times \mathrm{F} 2$ & 51.1 & 9.8 & 0.20 & 0.01 \\
\hline LP $\times$ F257 & 52.7 & 9.4 & 0.19 & 0.01 \\
\hline $\mathrm{LP} \times \mathrm{F} 2$ & 48.4 & 10.3 & 0.18 & 0.01 \\
\hline POOL4 & 54.9 & 8.9 & 0.22 & 0.01 \\
\hline F257 & 40.0 & 11.7 & 0.18 & 0.01 \\
\hline F2 & 33.1 & 12.5 & 0.17 & 0.01 \\
\hline F244 & 61.9 & 6.9 & 0.19 & 0.01 \\
\hline LP & 44.2 & 11.0 & 0.18 & 0.01 \\
\hline W64A & 48.7 & 10.3 & 0.20 & 0.01 \\
\hline LT & 49.0 & 10.2 & 0.19 & 0.01 \\
\hline B73 & 45.3 & 10.9 & 0.19 & 0.01 \\
\hline
\end{tabular}
a Estimated leaf tip appearance rate at $15^{\circ} \mathrm{C}$ vs estimated leaf tip appearance rate at $20^{\circ} \mathrm{C} .{ }^{b}$ Soil temperature at which the mean leat
tip appearance rate is estimated at zero by the linear regression. ${ }^{c}$ Mean value observed during the whole experiment.

a lower slope (0.0241 vs 0.0306$)$, suggesting that under these conditions factors other than mean soil temperature during the sampling period were affecting the leaf tip appearance rate.

In conclusion, tolerance to temperature variation in the range $12-25^{\circ} \mathrm{C}$ was found to differ among genotypes. However, the choice among genotypes may be difficult for the breeder, since a more 'tolerant' genotype is not necessarily optimal. For example, F244 showed a lower mean leaf tip appearance rate than the 'susceptible' inbred W64A (table IV). This means that the strategy of choosing a genotype which reacts strongly to an elevation of temperature ('susceptible') may be valuable when cool temperatures are encountered only for short periods.

\section{Leaf elongation rate}

The same approach was used in analyzing the elongation rates for leaves 6,9 and 12. Mean soil temperature was again the best predictor of leaf elongation rate except that, for leaf 12 , the mean air temperature was a slightly better predictor. Soil temperature was then used, as previously, as the covariate in the general linear model analysis (table $\mathrm{V}$ ). The coefficients of determination were in all cases very high $\left(R^{2}>85 \%\right)$. This character was much more reliable than leaf tip appearance rate (fig 4).
The effect of planting date was highly significant for leaf 6 , but decreased for leaf 9 and disappeared for leaf 12 . The effect of genotype was always highly significant, for both intercept and slope (table V).

The genotypes were distributed over several groups, depending on the leaf number (table $\mathrm{VI}$ ). For leaf 6, LP $\times$ F257, LP $\times$ F2, POOL4 and F2 showed a highly negative intercept and a high slope. F257, F244, W64A and B73 showed a slightly negative intercept and a low slope. The results for the degree of tolerance, the ATT, and the mean leaf elongation rate led to further conclusions (table VII). Among the inbreds, it was possible to say that F2 was more susceptible to temperature variation (low degree of tolerance and high ATT) while B73 was more tolerant (high degree of tolerance and low ATT). Among the hybrids, POOL4 did not appear to be more tolerant to temperature variation (medium degree of tolerance and ATT) but showed a high mean leaf elongation rate over the whole temperature range encountered (table VII). F257 x F244 and F244 x F2 appeared to be the most tolerant hybrids but did not perform as well as POOL4. Compared to leaf tip appearance rate, the correlation between intercept and slope was lower. The ranking for ATT, therefore, was different from the ranking for linear regression estimates. Some of these genotypic differences are very useful to the breeder. For example, compared with LP and LT, F257 and W64A (respectively), can be eliminated 


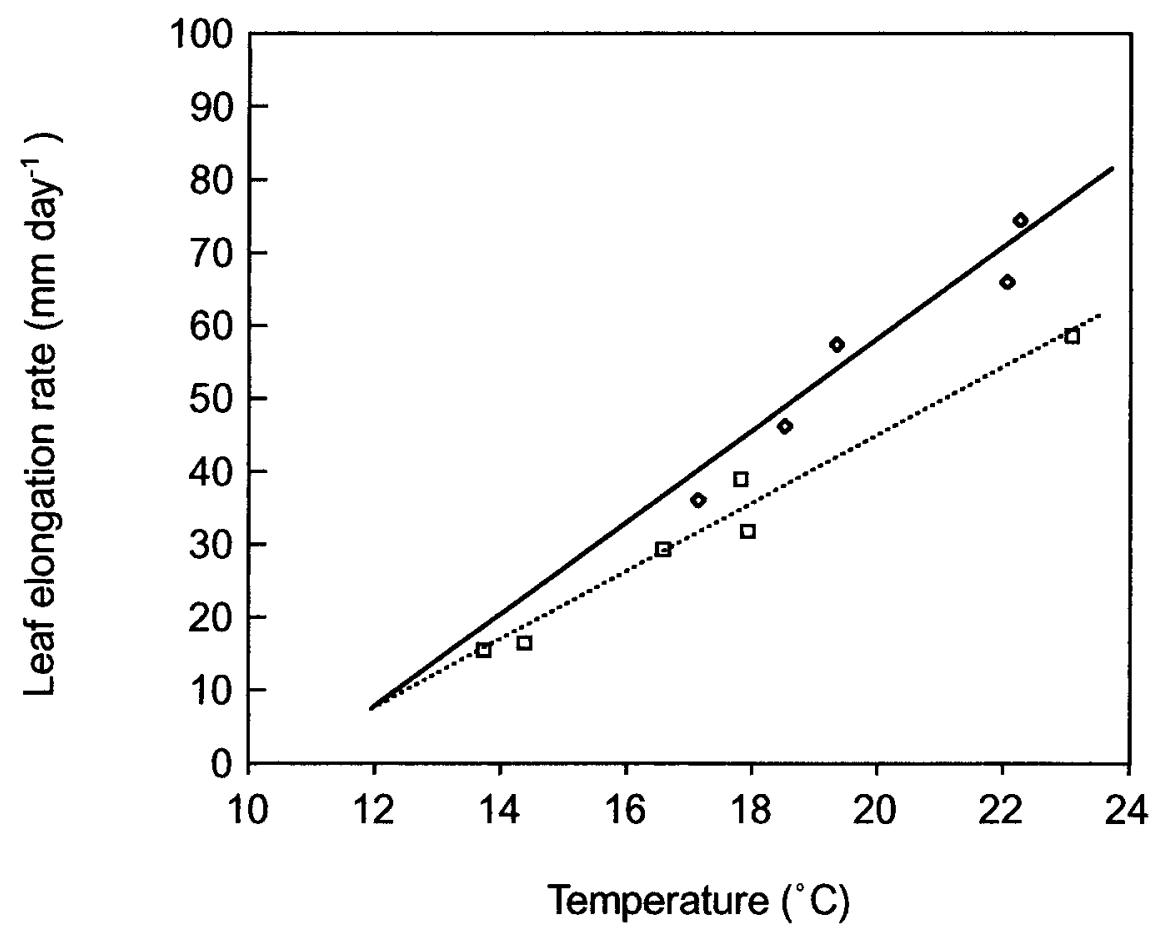

Fig 4. Elongation rate of leaf 9 for the maize hybrid F244 x F2 in relation to mean soil temperature after early planting (4 April 1991) and late planting (10 May 1991) in the north of France. The points plotted represent the means of the 3 replications; ---- $\square----$ early planting date, $Y=-47.9+4.64 X ;-\gamma$ - late planting date, $Y=-66.9+6.28 X$.

because they showed the same degree of tolerance (same ATT, as explained in fig 1), but a very small slope, meaning that, at each temperature, they did not perform as well as other genotypes. The results obtained here for the leaf 6 are hard to compare with those obtained by Watts (1972) for leaf 5 in controlled conditions (fig 5). In Watts' experiments, root temperature was kept constant at $25^{\circ} \mathrm{C}$ when air temperature was allowed to change, or vice versa, and therefore the effect of extreme treatments was less than if both temperatures had been allowed to change together.

The results for leaf 9 were quite different. First, for almost all genotypes, mean leaf elongation rate increased and degree of tolerance decreased. The ranking among genotypes for these characters changed. Some of these differences could be related to stem elongation, which was involved in the way of measuring the elongation of leaf 9 . Other differences could be explained by the temperature interval for which the temperature response was defined: approximately $14-18^{\circ} \mathrm{C}$ for leaf 6 and $17-23^{\circ} \mathrm{C}$ for leaf 9 (table VII). In the case of leaf 9 , the ATT, which was very different from the temperature range, was estimated with less precision and a greater degree of extrapolation. The hybrids and LP showed a highly negative intercept and a high slope (table VI), but the inbred LP showed a higher ATT (table VII) suggesting that it was very susceptible to decreasing temperature (degree of tolerance $23 \%$ ). In contrast, the hybrids appeared rather tolerant, and also responded to increasing temperature (high slope). Among the inbreds, surprisingly, F2 had the highest intercept, the lowest slope and the lowest ATT. This suggested that this very early genotype did not respond to favorable temperature, perhaps because of the appearance of a new sink due to early stem elongation. The same observation was made for leaf 12 for 2 other early genotypes, F244 (table VI) and F257 (results not shown). The temperature responses, as well as the mean leaf elongation rate obtained here for the hybrids under field conditions are very consistent with those obtained by Hesketh and Warrington (1989) for leaves 7-9 of 2 hybrids under controlled conditions (fig 5 ).

The differences among genotypes for leaf 12 were less significant. Only 3-4 groups were identified as being significantly different (table VI), but the range of the values remained the same as for leaf 9 . The ATT (table VII) decreased for most of the genotypes, and especially for the earliest ones (F244, LP x F2). For these genotypes also, 
Table V. General linear model analysis on leaf elongation rate using mean soil temperature as covariate, for 12 maize genotypes grown at 2 planting dates in the north of France in 1991.

Source of variation

Leaf 6

Temperature

Genotype

Planting date

Temperature $x$ genotype

Temperature $\mathrm{x}$ planting date

Genotype $x$ planting date

Temperature $x$ genotype $x$ planting date

Error

$\begin{array}{ll}\text { Mean } & 15.7 \mathrm{~mm} \cdot \mathrm{d}^{-1} \\ \text { CV } & 15.5 \% \\ R^{2} & 0.893\end{array}$

Leaf 9

Temperature

Genotype

Planting date

Temperature $x$ genotype

Temperature $x$ planting date

Genotype $x$ planting date

Temperature $x$ genotype $x$ planting date

Error

$\begin{array}{ll}\text { Mean } & 43.0 \mathrm{~mm} \cdot \mathrm{d}^{-1} \\ \text { CV } & 13.1 \% \\ R^{2} & 0.904\end{array}$

Leaf 12

Temperature

Genotype

Planting date

Temperature $x$ genotype

Temperature $x$ planting date

Genotype $x$ planting date

Temperature $\mathrm{x}$ genotype $\mathrm{x}$ planting date

Error

$\begin{array}{ll}\text { Mean } & 52.5 \mathrm{~mm} \cdot \mathrm{d}^{-1} \\ \text { CV } & 13.9 \% \\ R^{2} & 0.856\end{array}$
Df

Mean square

$\mathrm{F}$ value

1

11

1

11

1

11

11

2666

28362

112

1664

193

2848

138

161

6
$4801.64^{* * \star}$

$18.91^{\star \star \star}$

$281.71^{\star \star \star *}$

$32.75^{\star \star \star}$

$482.20^{\star \star \star}$

$23.30^{* * *}$

$27.25^{\star * \star}$

$\begin{array}{rr}144163 & 4515.84^{\star \star \star} \\ 644 & 20.17^{\star \star \star} \\ 1330 & 41.65^{\star \star \star} \\ 1332 & 41.74^{\star \star \star} \\ 3340 & 104.62^{\star \star \star} \\ 128 & 4.01^{\star \star \star} \\ 123 & 3.87^{\star \star \star}\end{array}$

1978

32

48490
106
3
253
74
91
94

$903.35^{\star \star *}$

1.98 *

0.05 NS

$4.72^{\star * *}$

1.38 NS

$1.70 \mathrm{NS}$

$1.75 \mathrm{NS}$

NS, ${ }^{*},{ }^{\star \star},{ }^{\star \star *}$ Non-significant, significant at the $0.05,0.01$ and 0.001 probability leveis, respectively.

mean leaf elongation rate increased relatively less, suggesting that this character was affected by some factor other than temperature, such as competition with the elongating stem. The higher values of tolerance could also mean that the plants did not respond fully to the favorable tem- peratures. This result mainly shows the low accuracy of parameter estimations associated with leaf 12 , and suggests that the elongation rate of this leaf was not a good criterion for comparing the response of different genotypes to temperature variation. 
Table VI. Estimate, standard error (SE), and grouping for the parameters of the general linear model analysis performed on leaf elongation rate using mean soil temperature as covariate, for 12 maize genotypes grown at 2 planting dates in the north of France in 1991.

Genotype

Leaf 6

$\mathrm{F} 257 \times \mathrm{F} 244$

$\mathrm{F} 244 \times \mathrm{F} 2$

$\mathrm{LP} \times \mathrm{F} 257$

$\mathrm{LP} \times \mathrm{F2}$

POOL4

F257

F2

F244

LP

W64A

LT

B73

Average

Leaf 9

$\mathrm{F} 257 \times \mathrm{F} 244$

$\mathrm{F} 244 \times \mathrm{F} 2$

$\mathrm{LP} \times \mathrm{F} 257$

$\mathrm{LP} \times \mathrm{F} 2$

POOL4

F257

F2

F244

LP

W64A

LT

B73

Average

Leaf 12

F257 x F244

$\mathrm{F} 244 \times \mathrm{F} 2$

LP x F257

$\mathrm{LP} \times \mathrm{F} 2$

POOL4

$\mathrm{F} 257^{\mathrm{b}}$

$\mathrm{F} 2 \mathrm{~b}$

F244

LP

W64A

LT

B73

Average
Intercept $\left(m m . d^{-1}\right)$

Estimate SE Grouping a

$-28.9$

$-22.6$

$\pm 1.8$

c

$-36.3$

$\pm 2.0$

$\pm 1.7$

$-43.1$

$\pm 1.7$

$-38.9$

$\pm 1.9$

def

b

a

$a b$

$-22.1$

$-42.1$

$\pm 1.5$

$\pm 2.3$

ef

a

$-21.6$

$\pm 2.1$

$\pm 3.1$

$\pm 2.7$

$-20.5$

$\pm 2.5$

$-28.7$

$\pm 3.3$

ef

cole

ef

cd

$-16.3$

$\pm 0.7$

$-29.0$

$\pm 3.4$

bc

cd

\pm 3.9
+5.5

cde

$\pm 7.4$

$a b c$

$-71.4$

$\pm 3.5$

a

$-44.0$

$\pm 5.0$

efg

$-18.3$

$\pm 3.5$

$\pm 7.0$

h

cdef

$-75.0$

$\pm 5.2$

$\pm 5.7$

$a b$

$-48.1$

$\pm 4.2$

defg

$-34.6$

$\pm 5.4$

fg

$\pm 1.5$

$-53.0$

$-59.2$

$\pm 6.5$

$\pm 7.2$

a

$a b$

$-44.1$

$\pm 5.3$

$\pm 10.4$

$a b$

$-25.0$

$\pm 5.1$

bc

bc

$-15.2$

$\pm 13.2$

$\pm 12.5$

$-53.9$

$\pm 10.7$

c

$a b$

$-47.3$

$\pm 10.4$

$\pm 10.3$

$a b c$

$a b$

$-30.3$

$\pm 3.0$

bc
Slope $\left(m m . d^{-1} \cdot{ }^{\circ} \mathrm{C}\right)$

Estimate SE Grouping a

2.45

3.51

3.94

3.81

2.11

3.28

2.13

2.57

1.96

2.76

1.92

$\pm 0.12$

$\pm 0.13$

$\pm 0.11$

$\pm 0.11$

$\pm 0.13$

$\pm 0.10$

$\pm 0.13$

$\pm 0.14$

$\pm 0.18$

$\pm 0.16$

$\pm 0.14$

$\pm 0.19$

de

fg

bc

a

$a b$

h

cd

gh

efg

$\mathrm{h}$

ef

2.78

$\pm 0.04$

$\pm 0.32$
5.95

5.45

$\pm 0.17$

$\pm 0.19$

$\pm 0.26$

$\pm 0.34$

$\pm 0.18$

6.43

6.98

3.88

2.62

$\pm 0.24$

$\pm 0.18$

$\pm 0.33$

$\pm 0.25$

$\pm 0.27$

$\pm 0.21$

$\pm 0.26$

3.52

$4.80 \pm 0.07$

6.65

5.95

$\pm 0.36$

$\pm 0.28$

$\pm 0.58$

$\pm 0.26$

4.72

5.69

2.86

$\pm 0.75$

$\pm 0.70$

$\pm 0.60$

$\pm 0.57$

$\pm 0.58$

a

$a b$

b

bc

b

5.25
3.88

$\pm 0.17$

bc

c

$a b$

d

e$$
\text { c }
$$$$
\text { d }
$$$$
\text { d }
$$

d

5.02

a For 2 estimates followed by the same letter, the contrast relative to their difference is not significantly different from zero at the 0.05 probability level. ${ }^{b}$ Not included in the analysis, because of missing values. 


\section{Consequences on the final characters}

As expected, there was an important genotypic variation for total leaf number (data not shown). The results concerning leaf area are reported in table VIII and also show the differences among genotypes. In this experiment, we were unable to relate the duration of leaf extension to temperature. This was probably due to the differences in the mean temperatures encountered during the

Table VII. Degree of tolerance to temperature variation, apparent threshold temperature (ATT), and mean leaf elongation rate for genotypes grown in the north of France in 1991.

\begin{tabular}{|c|c|c|c|c|}
\hline Genotype & $\begin{array}{c}\text { Tolerance } \\
\text { degree a (\%) }\end{array}$ & $\begin{array}{l}A T T^{b} \\
\left({ }^{\circ} \mathrm{C}\right)\end{array}$ & $\begin{array}{l}\text { Mean leaf elongation rate } \\
\qquad\left(m m \cdot d^{-1}\right)\end{array}$ & $\begin{array}{l}\text { Temperature range encountered } \mathrm{C} \\
\left({ }^{\circ} \mathrm{C}\right)\end{array}$ \\
\hline
\end{tabular}

\section{Leaf 6

F257 x F244
F244 x F2
LP x F257
LP x F2
POOL4

F257

F2

F244

LP

W64A

LT

B73

Leaf 9

$\mathrm{F} 257 \times \mathrm{F} 244$

$\mathrm{F} 244 \times \mathrm{F} 2$

$\mathrm{LP} \times \mathrm{F} 257$

$\mathrm{LP} \times \mathrm{F} 2$

POOL4

F257

F2

F244

LP

W64A

LT

B73

Leaf 12

F257 x F244

F244 x F2

LP $\times$ F257

$\mathrm{LP} \times \mathrm{F} 2$

POOL4

F257d

F2 d

F244

LP

W64A

LT

B73

$\begin{array}{rr}50.8 & 9.8 \\ 53.5 & 9.2 \\ 48.3 & 10.3 \\ 44.9 & 10.9 \\ 48.9 & 10.2 \\ 47.4 & 10.5 \\ 30.3 & 12.8 \\ 49.1 & 10.2 \\ 46.9 & 10.6 \\ 47.5 & 10.5 \\ 48.0 & 10.4 \\ 56.5 & 8.5\end{array}$

46.7

47.2

49.9

43.7

41.8

42.2

61.6

36.1

23.2

34.1

52.4

46.8

55.0

57.9

59.4

66.0

61.8

65.9

48.3

43.9

50.1

59.0

$17.7 \pm 0.2$
$16.2 \pm 0.2$
$19.3 \pm 0.2$
$19.3 \pm 0.2$
$21.4 \pm 0.2$
$11.3 \pm 0.2$
$9.9 \pm 0.3$
$12.0 \pm 0.2$
$13.5 \pm 0.3$
$10.5 \pm 0.3$
$15.0 \pm 0.3$
$14.0 \pm 0.3$

13.7-17.7

13.7-17.7

13.7-17.9

13.7-23.1

13.7-17.9

13.7-19.4

13.7-19.4

13.7-17.9

13.7-23.1

13.7-19.4

13.7-23.1

13.7-19.4

$54.4 \pm 0.5$

13.7-23.1

13.7-23.1

13.7-23.1

16.6-23.1

13.7-23.1

$55.6 \pm 0.8$

$58.4 \pm 0.5$

16.6-23.1

$32.7 \pm 0.5$

16.6-23.1

16.6-23.1

$32.4 \pm 0.8$

$34.9 \pm 0.5$

$28.5 \pm 0.6$

16.6-23.1

16.6-23.1

16.6-23.1

$37.4 \pm 0.4$
$32.3 \pm 0.5$

$16.6-23.1$

16.6-23.1

16.6-23.1

16.6-23.1

16.6-21.0

16.6-23.1

$37.5 \pm 0.9$
$45.7 \pm 0.8$
$31.7 \pm 0.7$
$44.8 \pm 0.7$
$41.5 \pm 0.6$

16.6-21.0

16.6-21.0

16.6-21.0

16.6-22.6

16.6-21.0

a Estimated leaf elongation rate at $15^{\circ} \mathrm{C}$ vs estimated leaf elongation rate at $20^{\circ} \mathrm{C}$. b Soil temperature at which the mean leaf elongation rate is estimated at zero by the linear regression. ${ }^{c}$ Temperature range encountered by each genotype during the growth of its leaf. $d$ Not included in the analysis, because of missing values. 


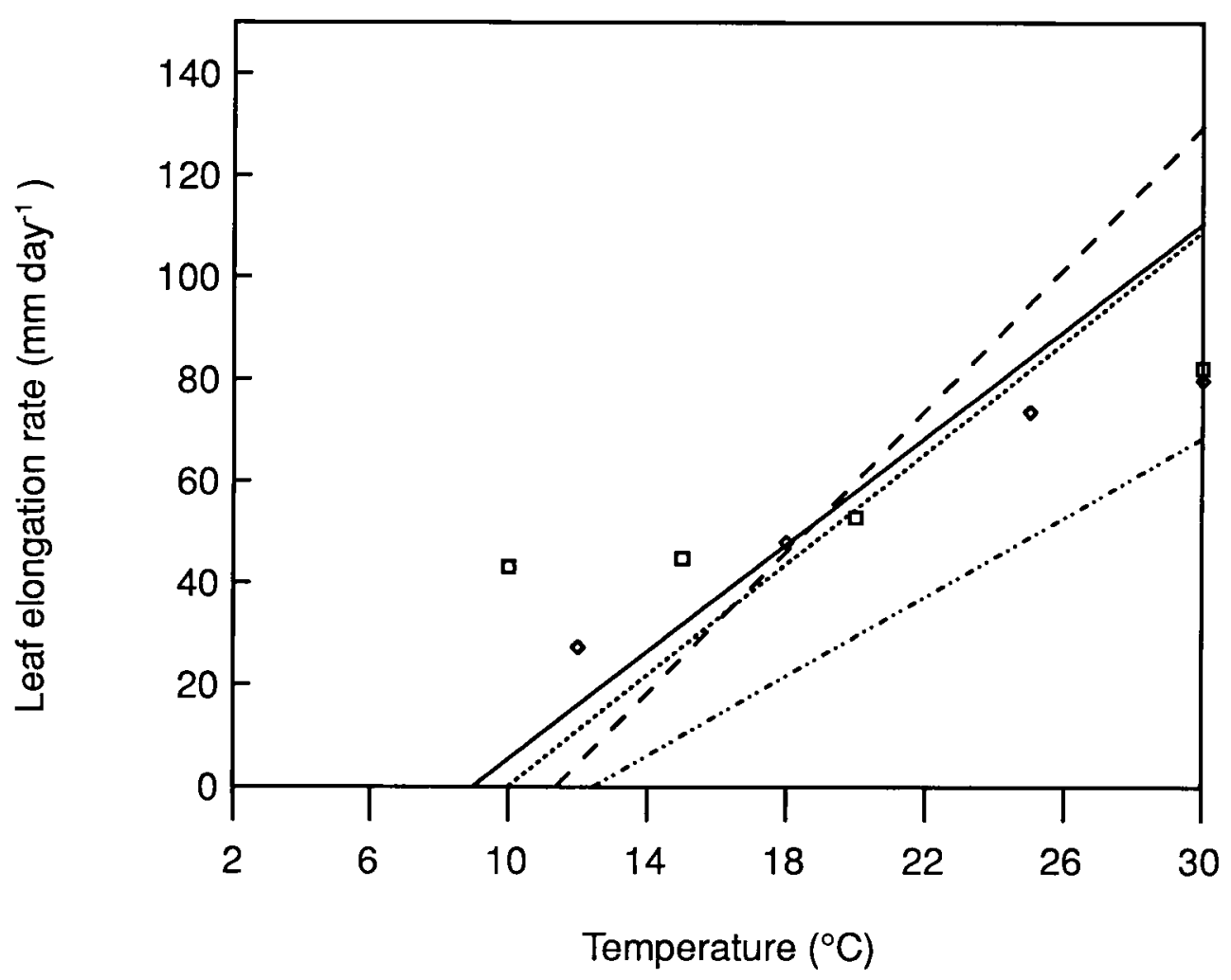

Fig 5. Relationships between maize leaf elongation rate and temperature derived from field or controlled environment studies. $\square$ : Watts (1972); soil temperatures kept at $25^{\circ} \mathrm{C}$; leaf 5. 0 : Watts (1972); air temperature kept at $25^{\circ} \mathrm{C}$; leaf 5 . - Hesketh and Warrington (1989); controlled conditions; leaves 7-11. _ - POOL4, leaf 9; -... LP x F257, leaf 9; ....... W64A, leaf 9; mean regression line for 2 planting dates in the north of France in 1991.

Table VIII. Area of the leaves 6, 9 and 12 for 12 maize genotypes grown in the north of France in 1991.

Genotype

Area of leaf $6\left(\mathrm{~cm}^{2}\right)$

Early planting Late planting

$\begin{array}{cc}57^{\mathrm{bc}} & 111^{\mathrm{bc}} \\ 72^{\mathrm{b}} & 119^{\mathrm{b}} \\ 72^{\mathrm{b}} & 157^{\mathrm{a}} \\ 102^{\mathrm{a}} & 178^{\mathrm{a}} \\ 55^{\mathrm{bcd}} & 127^{\mathrm{b}} \\ & \\ 22^{\mathrm{d}} & 64^{\mathrm{d}} \\ 37^{\mathrm{cd}} & 100^{\mathrm{bcd}} \\ 31^{\mathrm{cd}} & 76^{\mathrm{cd}} \\ 23^{\mathrm{d}} & 91^{\mathrm{bcd}} \\ 36^{\mathrm{cd}} & 70^{\mathrm{d}} \\ 36^{\mathrm{cd}} & 102^{\mathrm{bcd}} \\ 37^{\mathrm{cd}} & 71^{\mathrm{d}}\end{array}$

$\star \star \star$
$\star \star \star$
$\star \star \star$

$\mathrm{LP} \times \mathrm{F2}$

F257

F244

LP

W64A

B73
Area of leaf $9\left(\mathrm{~cm}^{2}\right)$

Early planting Late planting

$282^{\mathrm{cd}}$
$317^{\mathrm{bc}}$
$354^{\mathrm{b}}$
$405^{\mathrm{a}}$
$243^{\mathrm{de}}$
$125^{\mathrm{g}}$
$205^{\text {ef }}$
$156^{\mathrm{fg}}$
$173^{\mathrm{fg}}$
$109^{\mathrm{g}}$
$211^{\text {ef }}$
$119^{\mathrm{g}}$

Genotype

Planting date

Interaction

\section{$\mathrm{F} 244 \times \mathrm{F} 2$}

$\mathrm{LP} \times \mathrm{F} 257$

LT

Means followed by the same letter are not different at the 0.05 probability level. $\star \star \star$
$\star \star \star$
$\star \star *$
Area of leaf $12\left(\mathrm{~cm}^{2}\right)$

Early planting Late planting

$\begin{array}{ll}486^{b c} & 564^{b c} \\ 487^{b c} & 587^{b} \\ 405^{c} & 526^{c} \\ 516^{b} & 580^{b} \\ 597^{a} & 700^{a}\end{array}$

$333^{d}$

$397 \mathrm{e}$

$532^{\mathrm{c}}$

$338^{f}$

$490^{d}$

$426 \mathrm{e}$

$315^{d}$ 
growth of a given leaf being too small. For the 3 leaves studied, the duration of extension was significantly longer for the early planting date than for the late planting date $(P<0.001)$. Although this phenomenon might reduce the importance of the slower leaf elongation rate on the final area of the leaf, the leaf size remained smaller for the early planting date (48 vs $105 \mathrm{~cm}^{2}$ for leaf 6,225 vs $339 \mathrm{~cm}^{2}$ for leaf 9 , and 376 vs $469 \mathrm{~cm}^{2}$ for leaf 12). In contrast, the longer duration of the vegetative phase for the early planting date fully compensated for the lower leaf appearance rate and there was no significant difference in the final number of leaves between both planting dates (data not shown).

\section{CONCLUSIONS}

This study showed the importance of genetic differences for the response of leaf appearance rate and leaf elongation rate to temperature. It was carried out under field conditions, but the results were consistent with previous studies carried out under controlled conditions. It would therefore be possible to conduct such studies on a larger set of genotypes, since space is less limiting under field conditions. The information resulting from the test of some promising genotypes, could be used by the breeder in order to improve their ability to withstand low temperatures during early stages, and to develop their leaf area rapidly for maximum light interception. Leaf elongation rate was the most important characteristic, since it was almost exclusively determined by temperature under our field experimental conditions. Our results also indicated that the leaves 6-9 would give the most accurate information regarding the genotype responses to temperature. Unfortunately, leaf elongation is not an easy trait to measure. In our experimental conditions, we failed to use the final leaf area of some leaves as an indicator of temperature susceptibility of the genotypes. A wider use of different planting dates, years, and locations as well as a strict control of other environmental factors such as nitrogen, mineral and water supply could help to evaluate the degree of tolerance of genotypes based on such criteria.

The results obtained here should also be included in mathematical models describing whole crop development. Although some of these crop models involve temperature response for different processes, very few take genetic variation into account. For example, Hodges and Evans (1992) showed that thermal time require- ments per leaf, calculated with the CERES-maize algorithm (Jones and Kiniry, 1986; Ritchie et al, 1989 ), vary among years and hybrids. This algorithm uses a temperature threshold of $8^{\circ} \mathrm{C}$. We, however, showed that the apparent temperature threshold for leaf tip appearance rate could vary substantially (from 7.1 to $12.6^{\circ} \mathrm{C}$ ). The accuracy of different temperature response curves by genotype should be tested in such models. Even so, a better understanding of the effects of extreme temperatures, especially in terms of irreversible injuries, would be necessary. Our model was unable to give a general temperature response over the different environments tested. Precise studies in controlled conditions over a wider temperature range and with a reduced number of contrasted genotypes should provide suitable information, which would be particularly useful in adapting crop growth models to climates that are marginal for maize production.

\section{REFERENCES}

Brouwer R, Kleinendorst A, Locher JTH (1973) Plant Response to Climatic Factors. Proc Uppsala Symp (1970), Unesco Paris, France, 169-174

Cross HZ, Zuber MS (1972) Prediction of flowering dates in maize based on different methods of estimating thermal units. Agron J 64, 341-355

Cellier P, Ruget F, Chartier M, Bonhomme R (1993) Estimating the temperature of a maize apex during early growth stages. Agric For Meteoro/ 63, 35-54

Derieux M, Bonhomme R (1982) Heat unit requirements for maize hybrids in Europe. Results of the European FAO sub-network. I. Sowing-silking period. Maydica 27, 59-77

Freund RJ, Littell RC, Spector PC (1986) SAS System for Linear Models. SAS Institute Inc, Cary, NC, USA

Gilmore EC, Rogers JS (1958) Heat units as a method of measuring maturity in corn. Agron J 50, 611-615

Hardacre AK, Eagles HA (1980) Comparisons among populations of maize for growth at $13^{\circ} \mathrm{C}$. Crop $\mathrm{Sci}$ 20, 780-784

Hesketh JD, Warrington IJ (1989) Corn growth response to temperature: rate and duration of leaf emergence. Agron J 81, 696-701

Hodges T, Evans DW (1992) Leaf emergence and leaf duration related to thermal time calculations in CERES-maize. Agron J 84, 724-730

Jones CA, Kiniry JR (1986) CERES-Maize: A Simulation Model of Maize Growth and Development. Texas A \& M University Press, Temple, TX, USA

Levitt J (1980) Responses of Plants to Environmental Stresses. Vol 1. Chilling, Freezing and high Temperature Stresses. Academic Press, New York, USA 
Ritchie J, Singh U, Godwin D, Hunt L (1989) A User's Guide to CERES-Maize - V2.10. International Fertilizer Development Center, Muscle Shoals, AL, USA

Stewart DW, Dwyer LM (1994) Appearance time, expansion rate and expansion duration for leaves of field-grown maize. Can J Plant Sci 74, 31-36

Thiagarajah MR, Hunt LA (1982) Effects of temperature on leaf growth in corn. Can J Bot 60, 1647-1652

Tollenaar M, Daynard TB, Hunter RB (1979) Effect of temperature on rate of leaf appearance and flowering date in maize. Crop Sci 19, 363-366
Tollenaar M, Muldoon JF, Daynard TB (1984) Differences in rates of leaf appearance among maize hybrids and phases of development. Can $J$ Plant Sci 64, 759-763

Varlet-Grancher C, Bonhomme R, Chartier M, Artis P (1982) Efficience de la conversion de l'énergie solaire par un couvert végétal. Oecol Plant 3, 3-26

Watts WR (1972) Leaf extension in Zea mays. I. Leaf extension and water potential in relation to root-zone and air temperatures. $J$ Exp Bot 23, 704712 